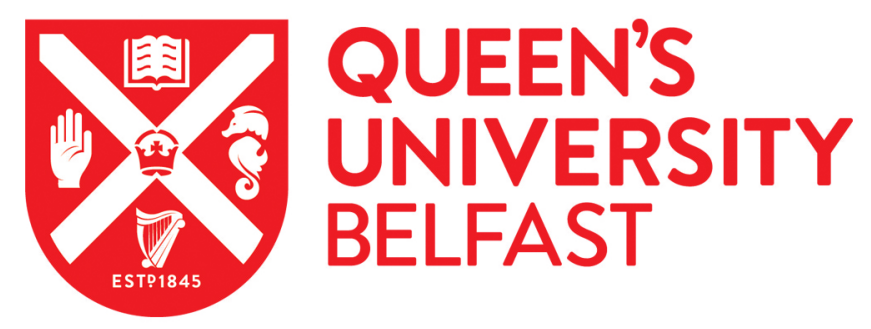

\title{
Feedback Kinetics in Mechanochemistry: The Importance of Cohesive States
}

Hutchings, B., Crawford, D., Gao, L., Hu, P., \& James, S. (2017). Feedback Kinetics in Mechanochemistry: The Importance of Cohesive States. Angewandte Chemie International Edition, 56(48), 15252-15256.

https://doi.org/10.1002/anie.201706723

\section{Published in:}

Angewandte Chemie International Edition

\section{Document Version:}

Peer reviewed version

\section{Queen's University Belfast - Research Portal:}

Link to publication record in Queen's University Belfast Research Portal

Publisher rights

(c) 2017 Wiley-VCH Verlag GmbH \& Co. KGaA, Weinheim. This work is made available online in accordance with the publisher's policies. Please refer to any applicable terms of use of the publisher.

\section{General rights}

Copyright for the publications made accessible via the Queen's University Belfast Research Portal is retained by the author(s) and / or other copyright owners and it is a condition of accessing these publications that users recognise and abide by the legal requirements associated with these rights.

Take down policy

The Research Portal is Queen's institutional repository that provides access to Queen's research output. Every effort has been made to ensure that content in the Research Portal does not infringe any person's rights, or applicable UK laws. If you discover content in the Research Portal that you believe breaches copyright or violates any law, please contact openaccess@qub.ac.uk. 


\title{
Feedback Kinetics in Mechanochemistry: The Importance of Cohesive States
}

\author{
Benjamin P. Hutchings, Deborah E. Crawford, Lei Gao, Peijun Hu, and Stuart L. James*
}

\begin{abstract}
Although mechanochemical synthesis is becoming more widely applied and even commercialised, greater basic understanding is needed if the field is to progress on less of a trial-and-error basis. We report that a mechanochemical reaction in a ball mill exhibits unusual sigmoidal feedback kinetics that differ dramatically from the simple first-order kinetics for the same reaction in solution. An induction period is followed by a rapid increase in reaction rate before the rate decreases again as the reaction goes to completion. The origin of these unusual kinetics is found to be a feedback cycle involving both chemical and mechanical factors. During the reaction the physical form of the reaction mixture changes from a powder to a cohesive rubber-like state, and this results in the observed reaction rate increase. The study reveals that nonobvious and dynamic rheological changes in the reaction mixture must be appreciated to understand how mechanochemical reactions progress.
\end{abstract}

$M$ echanochemical synthesis, in which solid starting materials are induced to react by grinding, attracts ever-increasing attention because it can provide low-waste, solvent-free chemical manufacturing as well as unique products. ${ }^{[1]}$ This approach to chemical synthesis is now being successfully scaled in continuous processes and even commercialised. ${ }^{[2]}$ However, many basic aspects of mechanochemical reactions remain poorly understood. For example, even the kinetics of such reactions have yet to be broadly investigated and interpreted, and as a result general reaction models are lacking. ${ }^{[3,4]}$ As such the field advances largely through trial and error. Recent work has revealed in some cases quite simple first- or second-order kinetics for ball milling reactions which support a "pseudo-fluid" reaction model. ${ }^{[3]}$ However, mechanochemical reactions are highly diverse, and reaction mixtures can undergo changes in their rheological properties during reactions, ${ }^{[4,5]}$ which are not taken into account in the above reaction models.

Here, we report that the kinetics of an apparently "simple" ball milling reaction are in fact quite complex and differ dramatically from the kinetics of the same reaction in the solution phase. Specifically, we observe sigmoidal kinetics, (superficially similar to those of auto-catalysed reactions),

[*] B. P. Hutchings, Dr. D. E. Crawford, L. Gao, Prof. P. Hu, Prof. S. L. James

School of Chemistry and Chemical Engineering

Queen's University Belfast

David Keir Building, Stranmillis Road, Belfast, BT9 5AG (UK)

E-mail: s.james@qub.ac.uk

(2) Supporting information for this article can be found under: https://doi.org/10.1002/anie.201706723. which indicate that a feedback mechanism is operating. A series of experiments has revealed the nature of this mechanism, the key factors in which are both chemical and mechanical.

Since the kinetics of covalent organic reactions have not been studied in detail under milling conditions, we chose as a model reaction the archetypal Knoevenagel condensation of vanillin and barbituric acid, (Scheme 1) first reported under mechanochemical conditions by Kaupp,${ }^{[6]}$ and investigated in planetary mills by Stolle et al. ${ }^{[7]}$ This reaction is also appropriate for study since all the organic components should remain predominantly solid throughout the reaction (the reactants and product have melting points of 83, 245 and $263^{\circ} \mathrm{C}$ respectively).

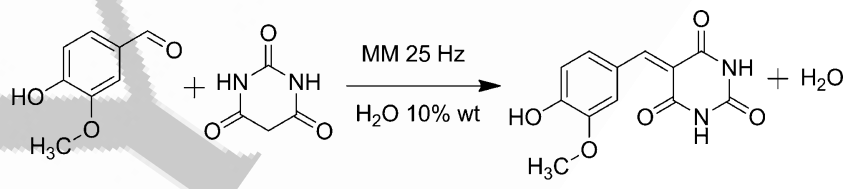

Scheme 1. The mechanochemical Knoevenagel condensation of vanillin and barbituric acid ( $\mathrm{MM}=$ mixer mill).

For comparison, the kinetics of the reaction were first measured in solution ( $\left[\mathrm{D}_{6}\right] \mathrm{DMSO}$, from ${ }^{1} \mathrm{H}$ NMR spectra) and were found to be relatively straightforward (Figure 1, blue data points), being satisfactorily modelled as first-order (see the Supporting Information).

For the milling experiments, the reaction was conducted at $0.5 \mathrm{~g}$ scale using a Retsch MM400 shaker-type ball mill. Addition of water $(10 \% \mathrm{wt})$ was required to enable full conversion within a practical timescale (40 minutes). Periodic sampling of a given reaction run would require stopping the mill and opening the jar, during which the reaction vessel would cool which could skew the results. Therefore, each data point was obtained from an individual reaction run which was then discarded. For each time point, several repeat runs were performed for each time point and data were averaged. A composite of the averaged raw conversion data is shown in Figure 1 (red data points). Strikingly, the kinetics of the milling reaction are sigmoidal, starkly contrasting the solution phase kinetics. In particular, there is an induction period during which the reaction is slow (reaching ca. $25 \%$ conversion after 25 minutes) followed by a dramatic increase in reaction rate (to give ca. $95 \%$ conversion within a further 10 minutes). Though related sigmoidal kinetics have been noted under mechanochemical conditions previously, ${ }^{[7]}$ the origin of this deviation from simple kinetic models, to our knowledge, has not been investigated or indeed commented 


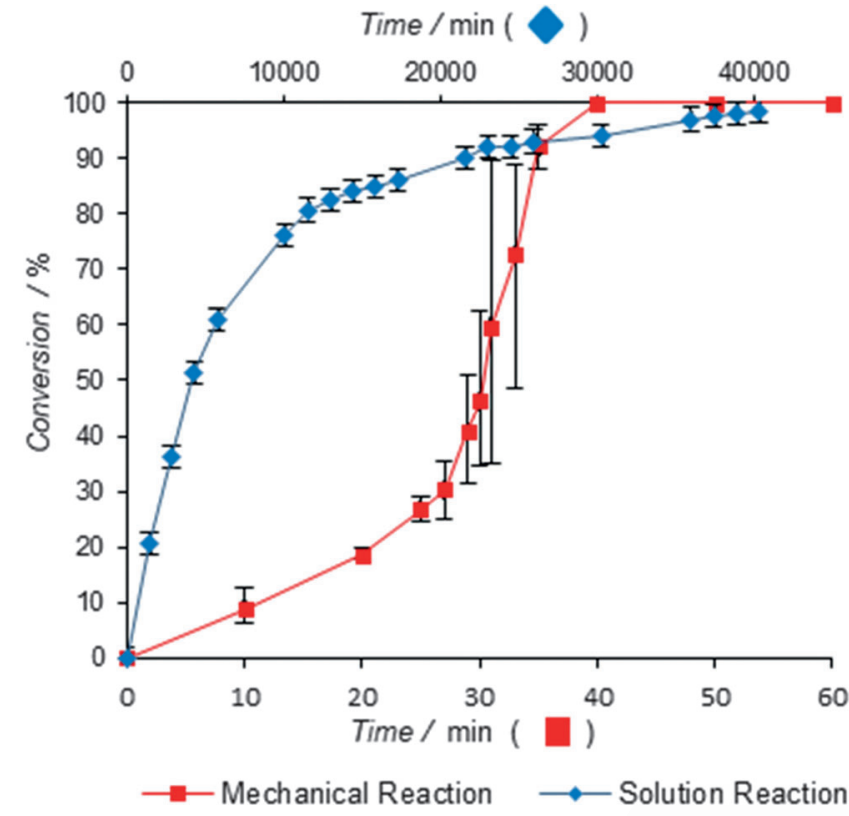

Figure 1. Comparison of conversion versus time for the Knoevenagel reaction in solution ( $\left.\left[D_{6}\right] D M S O\right)$ and under mechanochemical conditions (Mixer Mill, $25 \mathrm{~Hz}$ with added water 10\% wt). Error bars were calculated from three standard deviations from the mean of each dataset for each time point.

upon. Self-sustaining mechanochemical reactions in the context of inorganic materials are known ${ }^{[8]}$ which have superficially similar kinetics, that is, an induction period followed by an explosive increase in reaction rate, but those reactions are highly exothermic and, unlike the reaction studied here, proceed by combustion.

The effects of alternative milling frequencies $(15 \mathrm{~Hz}$, $30 \mathrm{~Hz})$ and scales $(0.25 \mathrm{~g}, 1.00 \mathrm{~g})$ on the reaction kinetics were also investigated. As might be expected ${ }^{[3]}$ the rate of reaction increased with increasing frequency (see Figure S6 in the Supporting Information) and decreased with increasing scale (see Figure S7). Generally, the greater the scale of the reaction, the longer was the induction time. Notably, in all cases where the reaction reached $25 \%$ conversion before the end of the run, similar sigmoidal kinetics were observed.

The sigmoidal kinetics observed here indicate that a positive feedback mechanism is operating, a phenomenon most familiar in the context of autocatalysed reactions. ${ }^{[9]} \mathrm{We}$ initially considered three factors which could potentially give rise to such kinetics: 1) formation of water as a by-product, which could act as an auto-generated solvent, or acid- or basecatalyst, 2) milling-induced reduction in particle size to a critical point at which the reaction suddenly accelerates, 3 ) internal heating due to a reaction exotherm and consequent rate acceleration. However, each of these possibilities was discounted in turn as follows.

Regarding the water by-product, this reaction is known to be catalysed in solution by both acid and base, ${ }^{[10]}$ and inhibited in aprotic media (such as chloroform), both as a bulk solvent and as an additive under milling conditions. However, when we increased the amount of water added at the start of the milling (to $20 \mathrm{wt} \%$ or $30 \mathrm{wt} \%$ ) or decreased it (to $5 \mathrm{wt} \%$ ) the reactions still exhibited similar sigmoidal kinetics (Figure $2 \mathrm{a}$ ). This indicates that the generation of one equivalent of water as a by-product ( $7 \mathrm{wt} \%$ ) is not directly responsible for the feedback kinetics.
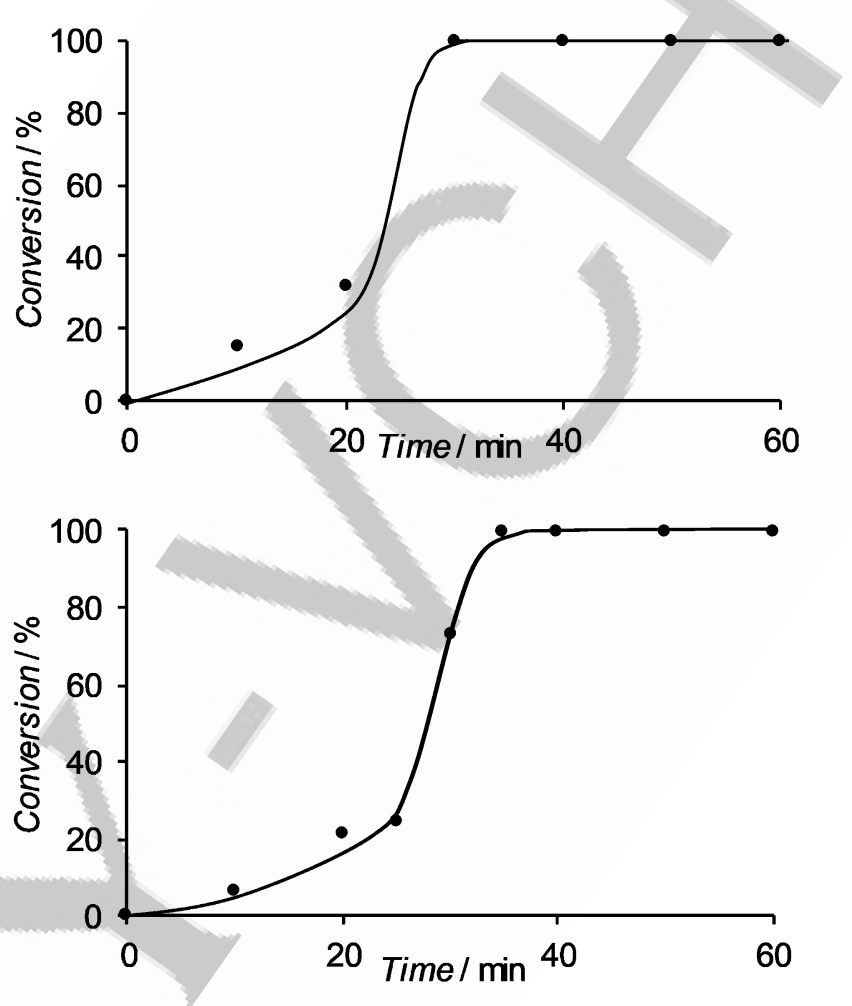

Figure 2. a) Reaction kinetics observed upon increasing the added water to $30 \mathrm{wt} \%$. b) Reaction kinetics observed after premilling of the reactants to reduce their particle size.

Regarding the reduction in particle size, milling of solids normally reduces their particle size, in turn increasing the surface area available for reaction, and this could potentially result in a sudden increase in reaction rate as the particle size reaches a critical value. To test this possibility, the reagents were pre-milled individually to reduce their particle sizes before being combined and milled in the reaction vessel. If the reduction in particle size was the cause of the observed increase in reaction rate, then premilling should cause the reaction to accelerate earlier. However, this was not observed (Figure 2b). In fact, premilling was found to slightly retard the reaction, which did not reach complete conversion until 50 minutes. Though counterintuitive, similar rate-decreasing effects of premilling have been reported in some inorganic reactions under mechanochemical conditions. ${ }^{[11]}$

Regarding a reaction exotherm, once the reaction is initiated, the rise in temperature due to an exotherm could in principle cause a run-away increase in the reaction rate. Indeed, over the temperature range $40^{\circ} \mathrm{C}$ to $70^{\circ} \mathrm{C}$, an unmilled solid mixture of starting materials and water $(10 \% \mathrm{wt}$, as in the milling experiments) when simply heated in a glass vial did exhibit increasing reaction rate with increasing temperature (Figure $3 \mathrm{a}$ ). Also, during the milling reactions, the temperatures of the outside of the jar, the inside of the jar 


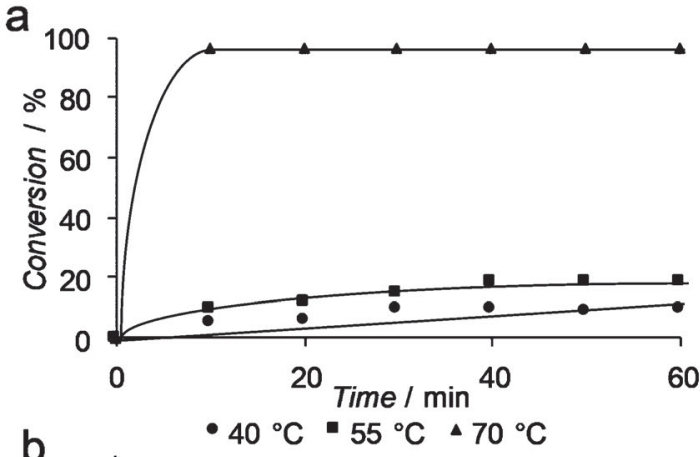

b

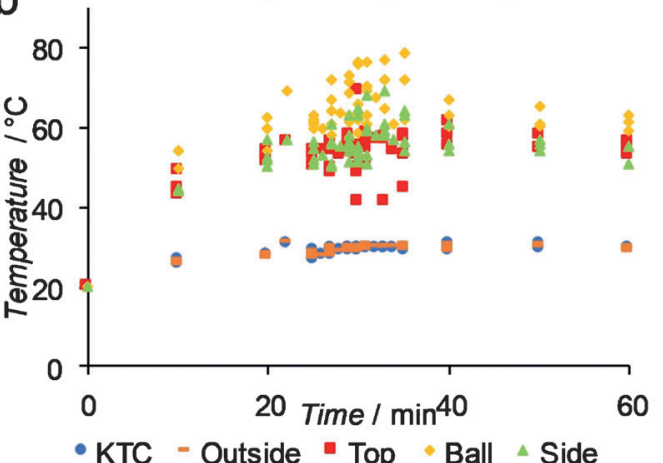

C

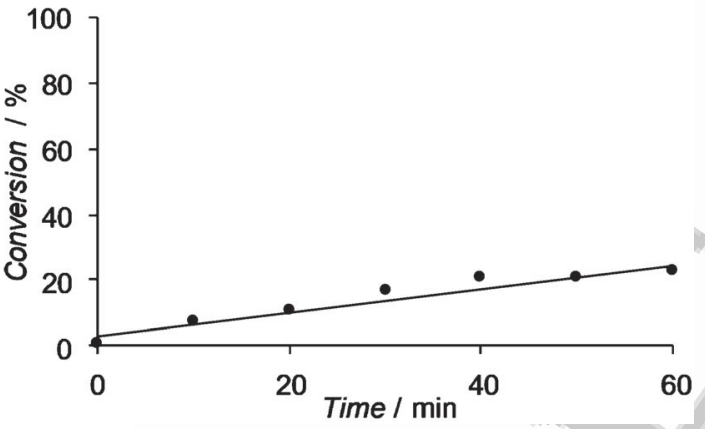

Figure 3. a) Conversion graph of the induced by heating an umilled mixture of reactants and $10 \mathrm{wt} \%$ water. b) Temperature monitoring of the milling reaction revealing the increase in temperature during the increase in reaction rate. The increase in temperature is greatest at the ball. c) Conversion graph of the reaction in a cryogenic mixer mill, at $25 \mathrm{~Hz}$ with water $10 \mathrm{wt} \%$, at $-195^{\circ} \mathrm{C}$.

and of the ball itself were all found to increase during the sigmoidal increase in reaction rate and to decrease after it (Figure $3 \mathrm{~b}$ ). To evaluate if this temperature increase could be due to the reaction exotherm, the Gibbs free energy change of the reaction was calculated with the Gaussian Software Package 09, performed by restricted exchange-correlation method B3LYP and basis set $6-311 \mathrm{G}++(\mathrm{d}, \mathrm{p})$ at $348.15 \mathrm{~K}$. This method gave the Gibbs free energy to be only $13.2 \mathrm{~kJ} \mathrm{~mol}^{-1}$ (see the Supporting Information). Taking into account the heat capacity of the steel jar and ball, this energy could only give rise to an average temperature increase of approximately $0.2^{\circ} \mathrm{C}$ over the jar and its contents (see the Supporting Information). Since a temperature rise of $12{ }^{\circ} \mathrm{C}$ was observed even at the outside of the jar and much greater increases were observed on the inside and at the ball, the reaction exotherm alone cannot account for the temperature increases seen. We also probed the effect of external cooling on the reaction on the reaction kinetics, by using a Retsch Cryomill, which employs liquid nitrogen to cool the outside of the mill jar to $-195^{\circ} \mathrm{C}$.

Remarkably, even at this low temperature, although the reaction was slower than without cooling, it did still progress, reaching approximately $23 \%$ conversion after 60 minutes (Figure $3 \mathrm{c}$ ). However, the sigmoidal acceleration of the reaction was not observed, possibly because the reaction had not progressed far enough. Collectively, these results indicate that, although an increase in temperature of the system may be at least partially associated with the feedback mechanism, the exotherm of the reaction alone is not large enough to cause the observed temperature change.

A fourth explanation for the sigmoidal kinetics was suggested by the observation of dramatic changes in the physical form of the reaction mixture as the reaction progressed. Specifically, the reaction mixture changed from a dry, free-flowing powder during the induction period to a cohesive rubber-like state that formed a robust coating around the ball during the sigmoidal increase in reaction rate (Figure 4 a, see also Figure S11), after which it returned again

a

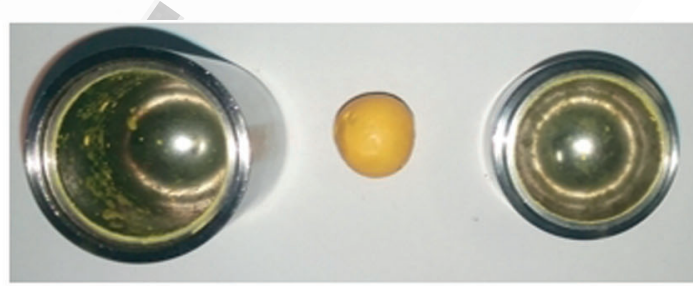

\section{b}
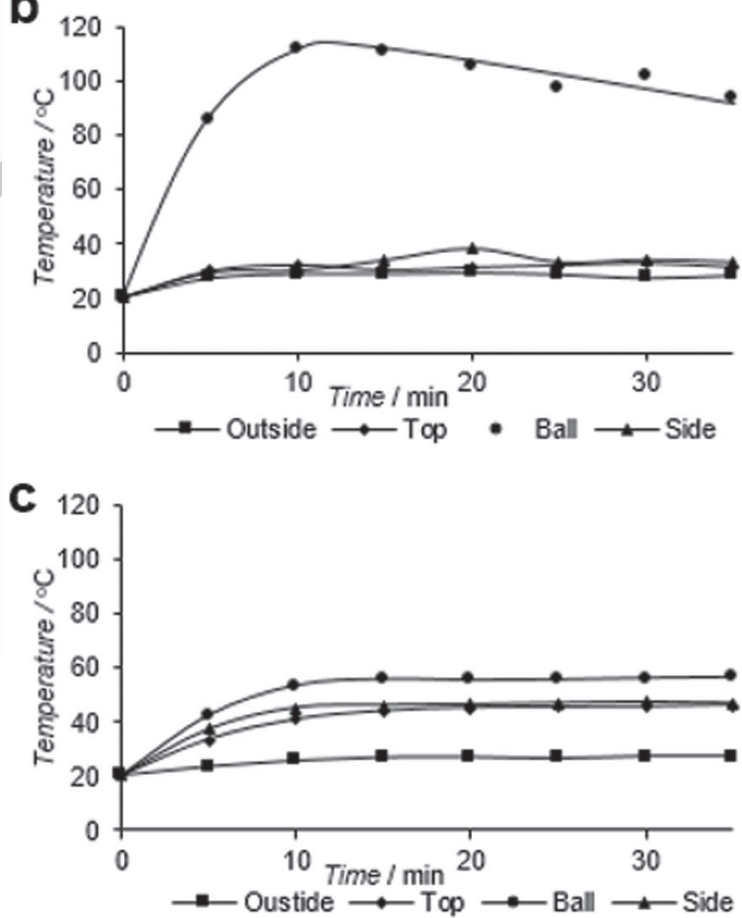

Figure 4. a) Photograph of the reaction vessel and grinding ball showing the conversion of the free-flowing powder to a plastic-like phase which coats the ball, and which occurs during the increase in reaction rate. b) Temperature graph using a PVA glue-coated ball. c) Temperature graph using cellulose.

These are not the final page numbers! 
to a free-flowing powder. During this cohesive state the sound of the mixer mill also changed notably. This type of change in the physical form of the reaction mixture has also recently been reported in the context of a ball milling co-crystal synthesis (described as a "snowball"), suggesting that it may be a general phenomenon in mechanochemical synthesis, although not often observed since the jars used normally are opaque. ${ }^{[5]}$ In fact, we have also observed this state to form transiently during the synthesis of the metal organic framework $\left[\mathrm{Zn}_{2} \text { (fumarate }\right)_{2}\left(4,4^{\prime}\right.$-bipyridine $\left.)\right] .^{[12]}$

The reasons for the formation of these cohesive states are likely to be complex and may result from a combination of several factors such as changes in the chemical composition, particle size and temperature of the reaction mixture as well as the compaction effects of milling.

On removal of the coated ball from the reaction vessel the cohesive state became brittle and began to revert to a powder after approximately one minute which may be due to evaporation of water and/or cooling and/or further progression of the reaction. As a result, it was not possible to characterise the rheological properties of the cohesive state in detail. However, clearly it can be expected that the characteristics of mass transfer including molecular diffusion during this state are likely to be dramatically different to those during the powder state. Therefore, the observed increase in reaction rate can be correlated to the formation of the cohesive state. In addition, it is well-documented that plastic or elastic deformation of related cohesive phases generates heat. ${ }^{[13]}$ To test whether this might be the origin of the observed increase in temperature during the reaction, we conducted control experiments using chemically inert materials with different rheological properties. First, a milling ball was coated with a layer $(0.6 \mathrm{~mm})$ of a chemically inert material (PVA glue), whose rubbery consistency mimicked the cohesive state transiently adopted by the reaction mixture. With this PVA-coated ball (in the absence of any other material such as reactants), milling did indeed result in a substantial rise in temperature (to $111^{\circ} \mathrm{C}$ ). The temperature increase was also greatest at the ball itself, as in the reaction system itself (Figure 4b). Second, we milled cellulose as a chemically inert powder to mimic the powder state of the reaction mixture. In this case an increase in temperature to only $47^{\circ} \mathrm{C}$ occurred. Therefore, it is possible that deformation heating during the cohesive state may contribute to the observed increase in temperature during the reaction under study.

Overall, the above observations can be depicted as a feedback cycle as illustrated in Figure 5. As the reaction progresses, changes in the reaction mixture, potentially combined with compaction from the milling process, cause it to change transiently from a powder to a cohesive rubberlike consistency. This in turn changes (accelerates in this case) the reaction kinetics. This shows clearly that the progression of this mechanochamical reaction results from an interplay of interplay of chemical and mechanical factors.

In conclusion, therefore, we note the following key points: 1) Sigmoidal feedback kinetics have been observed in a ball milling reaction, 2) these kinetics starkly contrast with those of the same reaction in solution, 3 ) the nature of the feedback

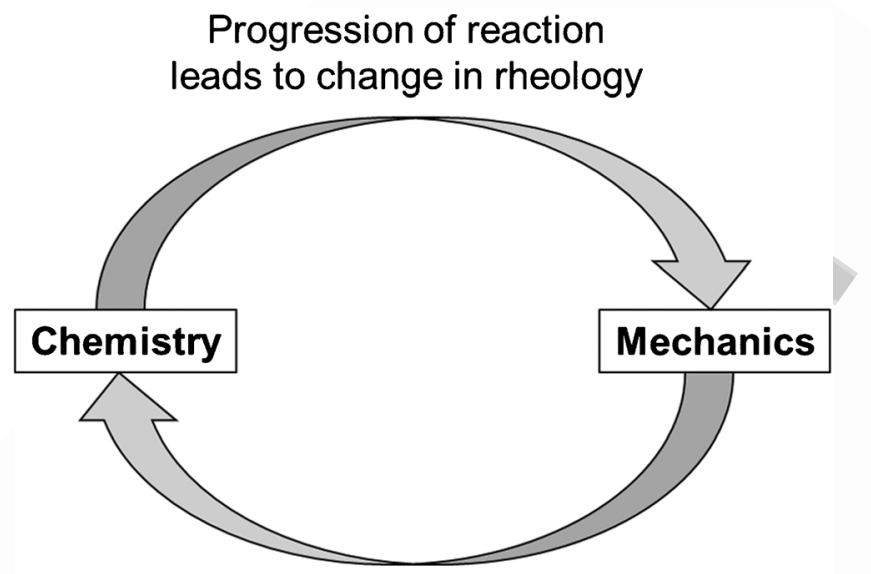

\section{Change in rheology leads to change in chemical kinetics}

Figure 5. Feedback cycle for the mechanochemical Knoevenagle reaction which accounts for the feedback kinetics and observed rheological changes.

loop has been investigated and involves an interplay of both chemistry and mechanics. Overall, this study highlights that the kinetics of mechanochemical reactions can be rather complex and mechanical factors need to be considered. Also, it must be borne in mind that these properties change over time. The dynamic nature of these properties must be appreciated in order to understand the progress, or otherwise, of mechanochemical reactions.

\section{Experimental Section}

All materials were purchased from Sigma Aldrich UK with $>98 \%$ purity and were used as received, unless indicated. Ball mill experiments were carried out using a Retsch MM400 mixer mill or a Retsch Cryomill. Temperature measurements were carried out using a Fluke 561 IR thermometer and the corresponding k-type thermocouple (KTC). The temperature measurements were taken at the outside of the ball via both the IR thermometer and the k-type thermocouple (outside, KTC), the top of the inside of lid if the mill jar (top). The side of the inside of the mill jar (side) and the grinding ball (ball). NMR analysis was carried out with a Bruker Advance DPX 300 with $\left[\mathrm{D}_{6}\right]$ DMSO as solvent.

Mixer mill experiments: vanillin $(0.29 \mathrm{~g}, 1.9 \mathrm{mmol})$, barbituric acid $(0.24 \mathrm{~g}, 1.9 \mathrm{mmol})$, the require amount of water and grinding ball (13.6 g) were added to a $25 \mathrm{~cm}^{3}$ stainless steel jar which was shaken at $25 \mathrm{~Hz}$ for the required amount of to time produce a powder, yellow if the reaction was incomplete, orange if complete.

Solution experiments: Vanillin $(0.29 \mathrm{~g}, 1.9 \mathrm{mmol})$, barbituric acid $(0.24 \mathrm{~g}, 1.9 \mathrm{mmol})$, water $(0.05 \mathrm{~mL})$ and grinding ball $(13.6 \mathrm{~g})$ were added to a $25 \mathrm{~cm}^{3}$ stainless steel jar which was shaken at $25 \mathrm{~Hz}$ for 1 minute to produce a yellow powder. A sample of this homogenised mixture $(0.07 \mathrm{~g})$ was dissolved in $\left[\mathrm{D}_{6}\right] \mathrm{DMSO}(0.6 \mathrm{~mL})$, and sealed in an NMR tube. The sample was monitored daily by ${ }^{1} \mathrm{H}$ NMR.

\section{Conflict of interest}

The authors declare no conflict of interest. 
Keywords: feedback cycles - kinetics - mechanochemistry · solid-state reactions s sustainable chemistry

[1] S. L. James, C. J. Adams, C. Bolm, D. Braga, P. Collier, T. Friščić, F. Grepioni, K. D. M. Harris, G. Hyett, W. Jones, A. Krebs, J. Mack, L. Maini, A. G. Orpen, I. P. Parkin, W. C. Shearouse, J. W. Steed, D. C. Waddell, Chem. Soc. Rev. 2012, 41, 413-447; G. A Bowmaker, Chem. Commun. 2013, 49, 334-348; G. W. Wang, Chem. Soc. Rev. 2013, 42, 7668-7700; A. Stolle, T. Szuppa, S. E. S. Leonhardt, B. Ondruschka, Chem. Soc. Rev. 2011, 40 , 2317-2329; T. Friščić, J. Mater. Chem. 2010, 20, 7599-7605; A. Bruckmann, A. Krebs, C. Bolm, Green Chem. 2008, 10, 1131 1141.

[2] R. Dhumal, A. Kelly, P. Coates, P. York, A. Paradkar, Pharm Res. 2010, 27, 2725; C. Medina, D. Daurio, K. Nagapudi, F. Alvarez-Nunez, J. Pharm. Sci. 2010, 99, 1693; D. Daurio, K. Nagapudi, L. Li, P. Quan, F.-A. Nunez, Faraday Discuss. 2014, 170, 235; D. Crawford, J. Casaban, R. Haydon, N. Giri, T. McNally, S. L. James, Chem. Sci. 2015, 6, 1645; D. E. Crawford, L. A. Wright, S. L. James, A. P. Abbott, Chem. Commun. 2016 52, 4215; D. E. Crawford, C. K. G. Miskimmin, A. B. Albadarin, G. Walker, S. L. James, Green Chem. 2017, 19, 1507; http://www. moftechnologies.com accessed $27^{\text {th }}$ May 2017.

[3] X. Ma, W. Yuan, S. E. J. Bell, S. L. James, Chem. Commun. 2014 50,1585-1587; I. Halasz, T. Friscic, S. A. J. Kimber, K. Uzarevic, A. Puskaric, C. Mottillo, P. Julien, V. Strukil, V. Honkimaki, R. E. Dinnebier, Faraday Discuss. 2014, 170, 203.
[4] A. A. L. Michalchuk, I. A. Tumanov. S. Konar, S. A. J. Kimber, C. R. Pulham, E. V. Boldyreva, Adv. Sci. 2017, 4, 1700132; H. Kulla, M. Wilke, F. Fischer, M. Rollig, C. Maierhofer, F. Emmerling, Chem. Commun. 2017, 53, 1664; K. Užarević, V. Štrukil, C. Mottillo, P. A. Julien, A. Puškarić, T. Friščić, I. Halasz, Cryst. Growth Des. 2016, 16, 2342.

[5] E. Boldyreva, Curr. Pharm. Des. 2016, 22, 4981-5000.

[6] G. Kaupp, M. R. Naimi-Jamal, J. Schmeyers, Tetrahedron 2003, $59,3753-3760$

[7] A. Stolle, R. Schmidt, K. Jacob, Faraday Discuss. 2014, 170, 267 286; C. F. Burmeister, A. Stolle, R. Schmidt, K. Jacob, S. Breitung-Faes, A. Kwade, Chem. Eng. Technol. 2014, 37, 857864.

[8] L. Takacs, Prog. Mater. Sci. 2002, 47, 355-414.

[9] A. J. Bissette, S. P. Fletcher, Angew. Chem. Int. Ed. 2013, 52, 12800-12826; Angew. Chem. 2013, 125, 13034-13061.

[10] M. L. Deb, P. J. Bhuyan, Tetrahedron Lett. 2005, 46, 6453-6456.

[11] V. Nachbaur, G. Tauvel, T. Verdier, M. Jean, J. Juraszek, D. Houvet, J. Alloys Compd. 2009, 473, 303-307.

[12] K. Fujii, A. Lazuen Garay, J. Hill, E. Sbircea, Z. Pan, M. Xu, D. C. Apperley, K. D. M. Harris, S. L. James, Chem. Commun. 2010, 46, 7572 .

[13] W. S. Farren, G. I. Taylor, Proc. R. Soc. London Ser. A 1925, 107, $422-451$; S. C. Chou, K. D. Robertson, J. H. Rainey, Exp. Mech. 1973, 13, 422-432.

Manuscript received: July 2, 2017

Revised manuscript received: September 11, 2017

Accepted manuscript online: October 12, 2017

Version of record online: 


\section{Communications}

Mechanochemistry

B. P. Hutchings, D. E. Crawford, L. Gao,

P. Hu, S. L. James*

III-IIII

Feedback Kinetics in Mechanochemistry:

The Importance of Cohesive States

Solid-state reactions: Unusual sigmoidal kinetics in mechanochemical reactions can be explained by a feedback loop involving chemical and mechanical fac-

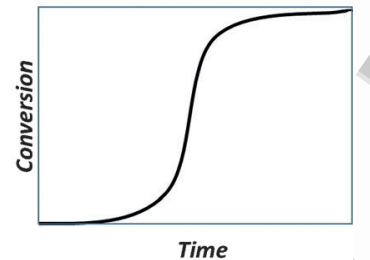

tors. During the reaction the physical form of the reaction mixture changes from a powder to a cohesive rubber-like state.

\section{Mechanochemie}

B. P. Hutchings, D. E. Crawford, L. Gao,

P. Hu, S. L. James*

IIII-IIII

Feedback Kinetics in Mechanochemistry: The Importance of Cohesive States

Festkörperreaktionen: Die ungewöhnliche sigmoidale Kinetik mechanochemischer Reaktionen kann mit einer Rückkopplungsschleife, die chemische und mechanische Faktoren einbezieht,

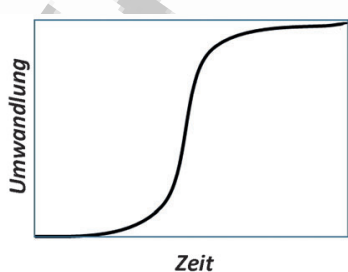

erklärt werden. Während der Reaktion verändert sich die physikalische Form der Reaktionsmischung von einem Pulver zu einem kohäsiven gummiartigen Zustand.

Please check that the ORCID identifiers listed below are correct. We encourage all authors to provide an ORCID identifier for each coauthor. ORCID is a registry that provides researchers with a unique digital identifier. Some funding agencies recommend or even require the inclusion of ORCID IDs in all published articles, and authors should consult their funding agency guidelines for details. Registration is easy and free; for further information, see http://orcid.org/.

Benjamin P. Hutchings

Dr. Deborah E. Crawford

Lei Gao

Prof. Peijun $\mathrm{Hu}$

Prof. Stuart L. James 